\title{
Spiritual leaders' experiences of a comprehensive HIV stigma reduction intervention
}

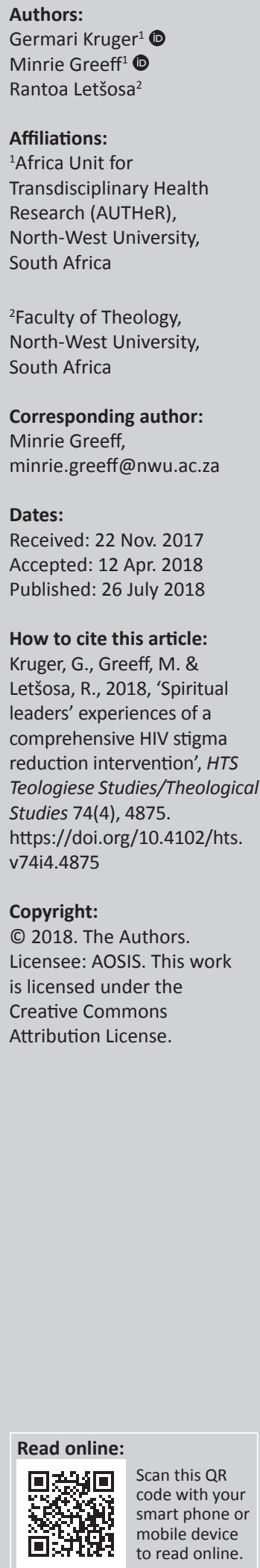

\begin{abstract}
HIV is a deadly reality in South African communities, where people living with HIV (PLWH) do not only face physical sickness but also severe stigmatisation. Literature shows that spiritual leaders (religious leaders/traditional healers) can have a very meaningful role in the reduction of HIV stigma. This article reports on part of a comprehensive community-based HIV stigma reduction intervention with PLWH and people living close to them, which included partners, children, family members, friends, community members and spiritual leaders. The focus of this article is on the experiences of spiritual leaders during and after the HIV stigma reduction intervention. The research took place in both an urban and rural setting in the North-West Province of South Africa and data collection was done by means of in-depth interviews with the spiritual leaders. The interaction with PLWH during the intervention activated new experiences for spiritual leaders: acceptance and empathy for PLWH, an awareness of their own ignorance, a stronger realisation of God's presence and a realisation that they could inspire hope in PLWH. A greater awareness was created of HIV and of the associated realities regarding disclosure and stigma. The inclusion of spiritual leaders as well as PLWH brought about a positive shift in the attitudes of communities through the increase of knowledge and understanding of HIV stigma. They saw themselves playing a much greater part in facilitating such a shift and in reducing HIV stigma in their own congregations and their communities at large.
\end{abstract}

\section{Introduction and background}

HIV remains a global issue, especially in Africa, which accounts for 25.7 million of the global estimate of 36.7 million people living with HIV (PLWH) (Joint United Nations Programme on HIV/AIDS 2018:16). In South Africa, specifically, the number of PLWH has significantly risen from an estimated 4.72 million in 2002 to 7.06 million by 2017 (Statistics South Africa 2017:7). People living with HIV thus represent $12.6 \%$ of the total South African population (Statistics South Africa 2017:7), showing that HIV increasingly affects the lives of all South Africans (Gilbert 2016:10). The increased availability of antiretroviral treatment (ART) has, however, transformed HIV and/or AIDS from a 'death sentence' (Park 2016) to a chronic illness (Ammon, Mason \& Corkery 2018:21; Treves-Kagan et al. 2016:87). Unfortunately, PLWH are not only faced with the burden of the physical side of the illness (WHO 2016) but also have to face severe stigmatisation (Joint United Nations Programme on HIV/AIDS 2015:9). HIV stigma influences every aspect of the PLWH's lives, including 'disapproval, rejection and sub-optimal services in health care settings' (Joint United Nations Programme on HIV/AIDS 2014:12; see also Gilbert 2016:11). It also impacts on how the community interact with PLWH (Treves-Kagan et al. 2016:87). HIV stigma further poses a barrier to the fulfilment of the holistic needs (physical, social and spiritual) of PLWH (Masquillier et al. 2015:214), with the result that PLWH experience 'mental health issues, social exclusion, rejection, high stress due to stigma and economic pressures' (Holzemer et al. 2007:547). HIV stigma thus leads to the marginalisation of PLWH within society (van der Walt \& Vorster 2016:3), which in turn hampers all efforts to end the HIV and AIDS epidemic (Joint United Nations Programme on HIV/AIDS 2014:2, 2018:68). HIV stigma, however, also impacts on the people living close (PLC) to PLWH, the community and health care services (French et al. 2015:95; Holzemer et al. 2007:548-549). Research over the past few years has shown that HIV stigma remains high in sub-Saharan Africa, as well as in South Africa (Abdullah in Human Sciences Research Council [HSRC] 2015:3).

\section{HIV stigma conceptualisation}

A review of the literature on stigma revealed that it is a complex phenomenon and that many authors have tried to define it. Alonzo and Reynolds (1995) rephrased Goffman's original definition 
and described stigma as being 'a powerful discrediting and tainting social label that radically changes the way individuals view themselves and are viewed as persons'. They then concluded that:

the stigmatized are a category of people who are pejoratively regarded by the broader society and who are devalued, shunned or otherwise lessened in their life chances and in access to the humanizing benefit of free and unfettered social intercourse. (p. 304)

Various conceptual frameworks and models attempted to clarify this complex phenomenon. Parker and Aggleton (2003:18, 19), for example, view stigma as social processes characterised by culture and power that reproduce inequality and exclusion. The conceptual model of Holzemer (used by this study) contextualises stigma occurrences as a process involving the environment, the healthcare system and the agent as part of the context. Holzemer et al. (2007:548) furthermore suggest that there are three types of stigma: received, internal and associated stigma. Received stigma is an overarching stigma that includes demeaning behaviour towards PLWH. Internal stigma is intrapersonal thoughts and behaviours that develop because of negative self-perceptions based on the person's HIV status. Associated stigma is directed at persons who interact with, live with, work with or are in any way connected with PLWH. HIV stigma can thus affect an individual PLWH and the PLC to PLWH.

\section{HIV stigma interventions}

To address this complex problem, researchers have aimed to find solutions through interventions to reduce HIV stigma. Brown, Macintyre and Trujillo (2003:53) conducted a systematic review as early as 2003 and found that interventions at that stage mainly focused on information-based approaches, skills-building approaches, counselling approaches and contact with affected groups. They found that the providing of information and the building of skills had the biggest impact but was nevertheless insufficient to permanently change attitudes or behaviour towards PLWH (Brown et al. 2003:65). A systematic review by Sengupta et al. (2011:1086) on studies targeting HIV stigma reduction could only recommend the replication of 3 (Apinundecha et al. 2007; Krauss et al. 2006; Wu et al. 2008) of the 19 designs, owing to insignificant results and ineffectiveness. The review found that too few interventions target HIV stigma; ineffective measures are used to evaluate HIV stigma reduction; and the studies lack public significance and internal validity (Sengupta et al. 2011:1084). They recommended that HIV stigma interventions should target issues of HIV stigma, use a validated instrument and should also measure health outcomes of interest (Sengupta et al. 2011:1085). Stangl et al. (2013:2, 7) investigated discrimination-reduction, stigma reduction, structural and biomedical interventions of 48 studies. They found that despite the progress made on HIV stigma reduction, too many studies focused on the 'individual-level drivers of stigma, such as knowledge, fear and attitudes' and an effort should be made to 'target multiple stigma domains at multiple levels'
(Stangl et al. 2013:10, 11). Gausset et al. (2012:1042) call for a shift in the conceptualisation of interventions from HIV prevention to the health promotion of PLWH. They argue that stigmatisation is multifaceted and complex because it does not only stem from 'fear, ignorance or inaccurate beliefs' but is 'also reinforced by official campaigns addressing HIV/AIDS’.

The HIV stigma reduction intervention work of Uys et al. (2009:1060) combined the three strategies of information sharing, increasing contact between nurses and PLWH and using empowerment to improve coping. Following work focusing on nurses and PLWH in healthcare settings in the five African countries, Uys et al. (2009:1065) found that PLWH involved in the intervention described a decrease in stigma and a significant increase in self-esteem. The nurses only reported an increase in voluntary testing, but there is a paucity in research focusing on HIV stigma reduction in communities. Little could be found on interventions that included spiritual leaders. Greeff (as part of the research published by French, Greeff \& Watson 2014:84) continued the HIV stigma reduction intervention by focusing on a comprehensive community-based HIV stigma reduction intervention with PLWH and PLC, and included PLWH and their partners (Louwrens, Greeff \& Manyedi 2016:11), family (Pretorius et al. 2016:189), friends, children, community members and spiritual leaders (French et al. 2014:84). The focus of this article is on the experiences of specifically the spiritual leaders during the latter HIV stigma reduction intervention. The term 'spiritual leader' is used to avoid discord, as both religious leaders and traditional healers fulfil the spiritual needs of PLWH. Mayers and Johnston (2008) highlight the diverseness of spirituality in the openness of their working definition of spirituality:

\footnotetext{
... [P]ersonal belief or faith also shapes an individual's perspective on the world and is expressed in the way he/she lives life. Therefore, spirituality is experienced through connectedness to God/a higher being; and/or by one's relationships with self, others or nature. (p. 273)
}

Therefore, spiritual needs (according to Baumgardner \& Crothers 2010:224) relate to the 'subjective, individual aspects of a person's religious experiences' (see also Kremer \& Ironson 2014:144 regarding the difference between spiritual and religious). Some studies (e.g. Ammon et al. 2018:26; Kremer \& Ironson 2014:144; Kwansa 2010:456) found that most PLWH seek some form of spiritual therapy to help them cope with HIV stigma.

\section{HIV stigma and spirituality}

The majority of South Africans (more than 80\%) indicated during the 2001 census that they had a religious affiliation (Statistics South Africa 2004:24). It is thus not surprising that many multicultural, religious or faith-based organisations are involved with fighting HIV on a family and community level that is less accessible to the government (Hanmer, Greenberg \& Keshavarzian 2009:54; World Council of Churches 2016). De la Porte (2016:5) explains that faith-based organisations provide 
'care, compassion and hope'. Most success stories are from initiatives by faith-based organisations that provide care, compassion and hope to PLWH, such as Shiselweni Home-Based Care (Van Wyngaard 2013:229-231), Let us Embrace (Thomas et al. 2006:45) and Churches, Channels of Hope (Landman 2014:6).

There are also less successful stories, for example, Olaore and Olaore (2014:24) who describe how the Christian community also contributed to the marginalisation and stigmatisation. $\mathrm{HIV}$ is sometimes seen as punishment from God for sins. Congregation members often condemn PLWH as immoral persons (Van der Walt \& Vorster 2016:1). In the early 2000s, Phillips (2005:328) noted that the church either became silent on the issue of stigma, or they denounced it, but either way the voice of the church was too quiet to make an impact or to change attitudes or behaviours. More recent studies have shown a change in how churches attempt to address HIV stigma. A qualitative study in Limpopo, South Africa, by Norder et al. (2015:1407) found that barriers preventing the involvement of churches in HIV healthcare are stigma resulting in non-disclosure, increased stigma because of the association between HIV and sexuality, and certain religious practices that interfere with adherence to medication. However, they also identified opportunities for health-religious collaborations, such as holistic HIV care to include spiritual aspects, utilising the church's social access to the community and the potential of churches for HIV dialogue because they are identified as safe and accepting places (Norder et al. 2015:1408). Similarly, Miller (2009:273-274) investigated the links between religion and HIV stigma by comparing religious entities as promotors or mitigators of stigma. In summary, she found that moral teachings of religious leaders that encourage separation between members that adhere to the teachings and those that do not can promote HIV stigma. On the contrary, some religious entities combat stigma through tolerance and compassion, providing support, utilising international networks, mobilising volunteers, providing value-based influence, representing a central authoritative voice and caring for vulnerable populations. She concluded that 'religious persons stigmatise no more, and in some case less, than society in general' (Miller 2009:281).

Traditional healers (or health practitioners) fulfil both a medical and spiritual role in African communities and are highly regarded, as they are often first consulted before a Western medical practitioner (Hodes 2014:121; Nemutandani, Hendricks \& Mulaudzi 2015:122). A traditional African view of health involves the relationship a person has with his or her ancestors, meaning that both physical and spiritual wellbeing are important to experience good health (White 2015:2). The study by Nemutandani et al. (2015:127, 130) found that although traditional healers are aware of the dangers associated with HIV, they are not adequately knowledgeable on HIV to serve as a first contact point, raising concerns about suggestions that PLWH are bewitched and that their traditional herbs and 'muthi' can cure HIV. Given the high number of patients that consult traditional healers, Nemutandani et al. (2015:131) recommend that health education and training workshops on HIV and/or AIDS and TB should be initiated. After reviewing and describing how traditional healers and the biomedical sector can successfully collaborate, Leclerc-Madlala, Green and Hallin (2016:188-191) argue that traditional healers are a valuable healthcare resource established in a community, but that building a trusting working relationship is of paramount importance.

The inclusion of religion and spirituality in healthcare has thus become prominent in recent years because it addresses the holistic nature of a person's affiliation (De la Porte 2016:7). At the 21st international AIDS conference, the World Council of Churches (2016) encouraged faith communities to become more involved because they can often work 'faster and cheaper' in bringing change in their communities. An intervention by Thomas et al. (2006:6) showed the advantages of addressing spiritual need. Slomka et al. (2013:455) also showed how addressing the spiritual needs of PLWH helped them cope with their daily challenges. Furthermore, some South African studies - such as Keikelame et al. (2010:68) and Clarke, Charnley and Lumbers (2011:16) - showed how spiritual leaders (and their organisations) are ideally situated to address and fight stigmatisation.

\section{Ethical consideration}

The research was approved by the North-West University Health Research Ethics Committee (NWU-00011-09-A1).

\section{Problem statement}

In the reviewed literature, it is evident that spiritual leaders are excluded from playing a noticeable role in the reduction of HIV stigma. Literature indicates that spiritual leaders are either supportive or negative towards PLWH. Limited research is available on the inclusion of spiritual leaders in HIV stigma reduction interventions or their experiences of being involved in such interventions. Involving spiritual leaders in HIV stigma reduction could be an advantage in the fight against HIV stigma in South Africa. However, an understanding of their experiences when included in such an intervention could be meaningful.

\section{Research question}

The question that arose from the reviewed literature and the problem statement was, what are spiritual leaders' experiences during and after a comprehensive HIV stigma reduction intervention that involved the spiritual leaders as well as PLWH in an urban and rural setting?

\section{Research aim}

The aim for this research was to explore and describe the spiritual leader's experiences during and after a comprehensive HIV stigma reduction and wellness enhancement intervention in both an urban and a rural setting. 


\section{Research method and design Research design}

This study was part of a bigger qualitative holistic multiple case study (Yin 2009:59) research project, including partners, children, family members, friends, community members and spiritual leaders (French et al. 2015:84). For this part of the study, a qualitative description approach was followed (Sandelowski 2000:337-339). The research took place in both an urban and rural setting in the North-West Province of South Africa, among mostly African Setswana-speaking people. Both communities are poverty-stricken with high unemployment rates and living in a province with the fourth largest numbers of HIV-infected people in the country (Statistics South Africa 2016:16).

\section{Sample}

The sample only included spiritual leaders from both the greater Potchefstroom district (as the urban group) and from the Ganyesa district (as the rural group) that were involved in the HIV stigma reduction intervention. Snowball sampling (Botma et al. 2010:201; French et al. 2014:108) was used to select the spiritual leaders. People living with HIV that were part of the larger intervention were asked to identify and choose a spiritual leader whom they trusted, who would be prepared to come to the intervention with them and who fitted the inclusion criteria. Spiritual leaders had to be at least 18 years of age; able to communicate freely in English, Afrikaans or Setswana; give consent to be interviewed and recorded; and could be either a traditional healer or a religious leader. The urban group of PLWH invited 6 spiritual leaders to attend, and the rural group invited 10 spiritual leaders. All these spiritual leaders agreed to be interviewed postintervention about their experiences during and after the intervention. The findings section consequently only describes the experiences of the spiritual leaders. Data saturation was achieved within 12 interviews, but all 16 spiritual leaders were interviewed.

\section{Data collection}

Data collection was done by means of in-depth interviews with the above-mentioned spiritual leaders after the HIV stigma reduction intervention. An independent research assistant obtained written informed consent from the participants. The spiritual leaders were assured that their participation was voluntary and they could withdraw at any time. The spiritual leaders were informed that they could possibly experience some emotional discomfort during the interviews but that psychological support would be available if needed. Appointments for the interviews were made with each participant at a venue they identified as safe, private and disturbance-free.

\section{The intervention}

Before the interviews, all the spiritual leaders were part of an HIV stigma reduction intervention that involved them as spiritual leaders and PLWH in the same intervention. The underlying tenets of the HIV stigma reduction intervention were to increase knowledge about HIV stigma and coping, to equalise the relationship between PLWH and PLC, and to empower both groups to become leaders in HIV stigma reduction in their communities. During the workshop, there were several presentations followed by activity-based group discussions. See Figure 1 for a representation of the HIV stigma reduction intervention. The facilitators of the workshops were a trained religious leader and a PLWH.

The intervention started with an initial 2-day workshop conducted with only the PLWH and focusing on their understanding of HIV stigma, identifying their personal strengths and how to handle disclosure in a responsible manner. Then the PLWH and their spiritual leaders were invited to attend a further 3 days. The first day focused on understanding and coping with HIV stigma, followed by an opportunity for PLWH and the spiritual leaders to share their experiences on stigma. The aim on the second day was to connect the knowledge and understanding gained on the first day, to train participants in basic project planning, so that they could then use this knowledge to constructively plan their own HIV stigma reduction project with other spiritual leaders in the community. Participants then had 1 month to implement their own project, with the researchers providing support and encouragement as well as monitoring the process. The Potchefstroom group's project was named Areageng [Let's build] and it was focused on teaching about HIV stigma and its impact in their community. The project was presented during a scheduled church service (with specific invitation to other local spiritual leaders) through singing and prayer in the service, putting up HIV stigma posters and performing a special song encouraging a united fight against HIV stigma. This was then followed by a psychodrama depicting the painful effects of stigma. The project of the Ganyesa group, named Modimo O rata bothle [God loves everyone], was split into three events: (1) a session at the tribal hall teaching others about HIV stigma, the different types of stigma and coping with stigma; (2) a psychodrama at a local primary school demonstrating HIV stigma; and (3) a candlelight ceremony at a local hall to advocate against HIV stigma and discrimination. During the events, participants also performed dances, and professional nurses assisted by providing voluntary counselling and testing services. The third (and last) workshop day took place a month later, after their projects where completed, giving them the opportunity to showcase their community projects and report back on it to relevant community stakeholders and the researchers, as well as to be evaluated by the research team on the success of their project.

The in-depth interviews with the spiritual leaders took place after the completion of the community project. One open-ended question for use in the in-depth interviews was formulated beforehand, discussed with experts and evaluated for suitability: 'How did you experience the workshop and project with the PLWH and other spiritual leaders in 

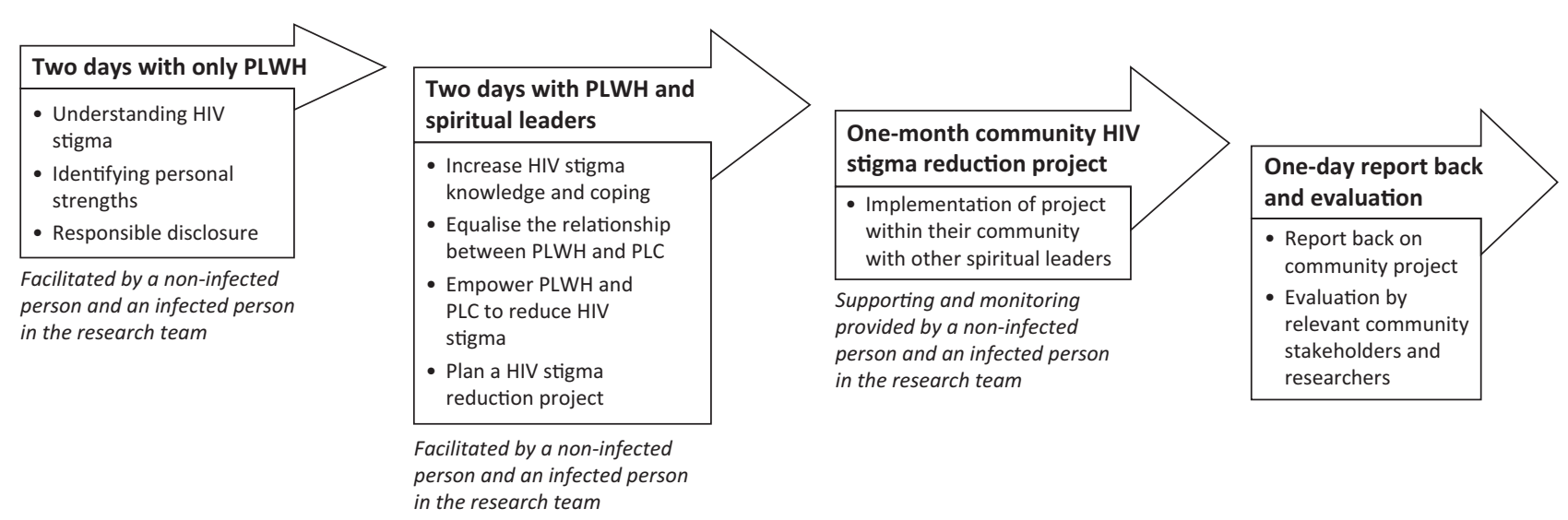

PLWH, people living with HIV; PLC, people living close.

FIGURE 1: Community-based HIV stigma reduction intervention.

the group?' The spiritual leaders were informed that an experienced researcher would make use of digital tape recordings which would be securely stored and passwordprotected. Communication techniques like paraphrasing, summarising, reflection, minimal verbal response and probing were used during the interview (Okun 1992:70-71). Interviews took an hour to an hour and a half to complete. Field notes were taken after each interview, focusing on methodological, theoretical and personal notes (Botma et al. 2010:218).

\section{Data analysis}

The digital voice-recorded interviews were transcribed verbatim for data analysis (Botma et al. 2010:214). The open coding process of Tesh (as cited in Creswell 2014:198) was followed to identify in vivo and descriptive codes. The researcher read the full text to get a sense of the whole, developed codes and coded the text. Subcategories, categories and themes emerged during the analysis. An independent co-coder also analysed the data to ensure trustworthiness. Consensus conversations confirmed the findings.

\section{Trustworthiness}

To ensure trustworthiness in this study, the researcher applied Lincoln and Guba's model (as cited in Botma et al. 2010:234-235). Prolonged engagement with the participants during the intervention, the project and the in-depthinterviews ensured truth value. The researcher reflected by writing field notes during and after the intervention and the interviews. Regular discussions among researchers enriched the process and improved credibility. Applicability was ensured through a well thought-through sample and a dense description of the research methodology. The possibility of an audit trail and the use of an independent co-coder during data analysis ensured consistency. Replication is possible because of a dense description of the study and data. An audit trail and reflexivity ensured neutrality. Authenticity is evident in the quotes that enrich the findings.

\section{Ethical consideration}

The researchers' previous studies in the community provided the trust relationship to continue with this study and to make use of non-governmental organisations (NGOs). Great care was taken with the inclusion of the PLWH in the larger study and they were always first approached through mediators to ensure that they had a choice as to whether they wanted to participate. The risk-benefit ratio analysis led to a workshop for the PLWH prior to their contact with others, to give them the necessary skills to responsibly disclose their statuses should they feel the need. Travel expenses were covered if they preferred a venue other than their own homes. The spiritual leaders were informed that their recorded interviews would be kept anonymous and confidential by marking them with a code instead of their names. Data were stored in a safe place with hard copies being locked away and electronic data on computers being passwordprotected. The data will be kept for 5 years.

\section{Findings and discussion}

The results reflect the findings of the 16 interviews that were conducted with the spiritual leaders. These findings are specifically focused on the experiences of the spiritual leaders. Three themes were identified during the analysis of the interviews with the spiritual leaders: Interaction with PLWH activated new experiences for spiritual leaders; an increased awareness of difficulties with HIV, disclosure and stigma; and the value of the HIV stigma reduction project. These three themes and their associated categories are visually represented in Figure 2, which provides a summative relational outlay between the themes and their associated categories. The discussion uses the structure of Figure 2, as well as enriching verbatim quotes from the spiritual leader's interviews.

\section{Interaction with people living with HIV activated new experiences for spiritual leaders}

The intervention encouraged participants to initiate contact with PLWH, making them realise that they can live and socialise with PLWH without fear of infection. Through 


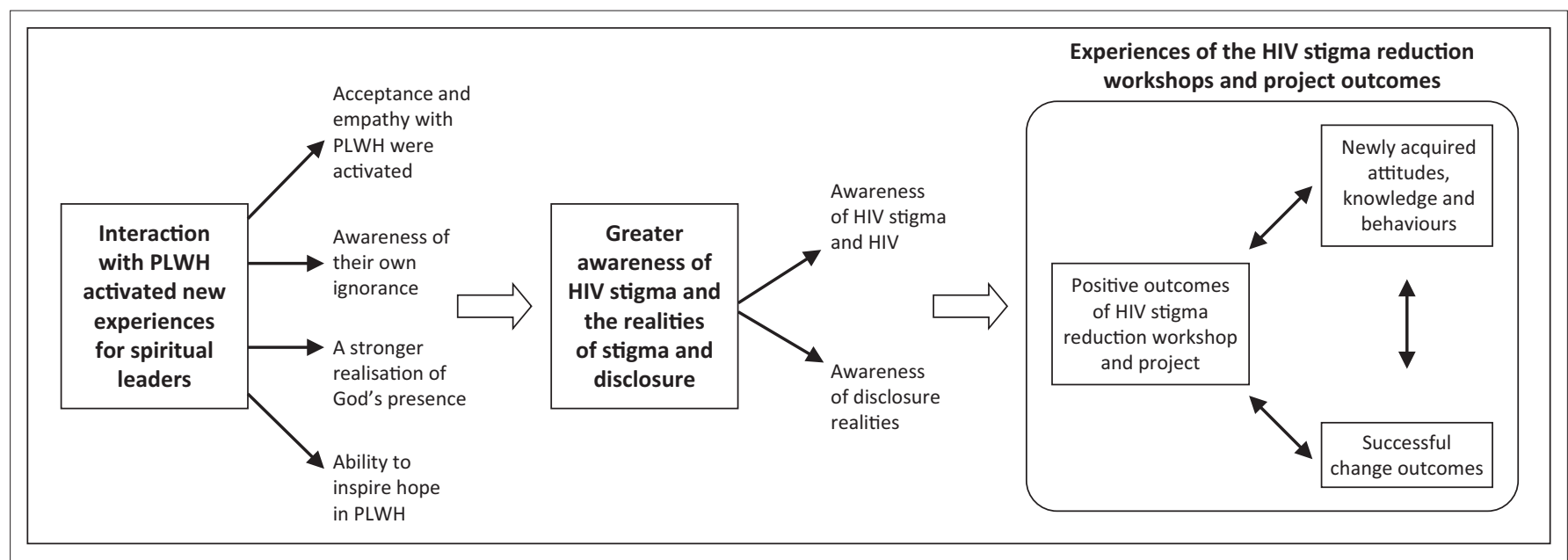

PLWH, people living with HIV.

FIGURE 2: Experiences of spiritual leaders.

engaging with PLWH during the workshop and project, participants began to learn from PLWH and realised that each PLWH has a different story to tell. Participants witnessed how PLWH accepted themselves and made peace within themselves.

There were four subcategories that showed the participants' experiences while interacting with PLWH during the workshops and projects of the HIV stigma reduction intervention.

\section{Acceptance and empathy with people living with HIV were activated}

The interactions between PLWH and the spiritual leaders during the workshops and projects lead to spiritual leaders accepting PLWH. This was especially true for the religious leaders and in the religious settings where exclusion is sometimes the order of the day:

'At church I'm the one who handles issues on health but they always told me that if it's a community thing like a convention, please don't recruit people who are positive, they mustn't come and cook or whatever because we are never going to eat their food ...'

This turned to acceptance after the project: '... but now the very same people are the ones who elect them for the cooking and even to be members of the committee'.

The interactions activated empathy with PLWH when they realised what painful experiences PLWH have to face when they disclose their HIV-positive status. These experiences varied from physical rejection ('...from the moment you disclose they will never hug you. That is it, no more hugs'.) to at times being more social and emotional in nature ('Why should I go to friends who are criticising me? My family has left me'.) The spiritual leaders also became sad because of all the deaths caused by HIV and particularly when they felt they could have supported their own loved ones that had already passed away. The participants recognised how PLWH are victimised within their own religious organisations and would then 'stop going to church because they were judged'. They realised their own shortcoming in providing support to PLWH ('In the church there is no one who stands up and speaks for those people who are discriminated against because they have HIV and AIDS'). Empathy became more visible through the spiritual leaders' honesty:

'Those who were crying, they started to see that I am open and that I am really with them. I cry with them because in the church, we cry with those who are crying. We rejoice with those who are rejoicing.'

\section{Awareness of their own ignorance}

Interacting with PLWH alerted participants to their own ignorance of HIV and the HIV stigma in their communities and the fear they felt towards PLWH. One spiritual leader remarked that before the intervention he felt that these things does not concern the church. I am a pastor, these things are not my problem'. Participants realised that their own negative emotions arose because they did not know about HIV or stigma and particularly because they do not think 'of the problem of HIV in relation to what the victims are suffering'.

\section{A stronger realisation of God's presence}

Participants experienced a stronger presence of God and of his love and care for everybody. They experienced God's presence during the workshops and project as if 'God was a part of it'. He helped, supported and strengthened the participants:

'I experience that sometimes God can make miracles. Sometimes you say I'm afraid to do this when I'm in front of the people, can I make it? Maybe I can't do this, but in the power of God, you find yourself being able to go and reach that.'

\section{Ability to inspire hope in people living with HIV}

Spiritual leaders recognised that they can inspire hope in PLWH because they became aware that 'HIV is not a death sentence'. This hope was often of a spiritual nature: 'I told them you have potential; God has given you potential. Being HIV-positive doesn't mean you won't be able to fulfil 
your potential' and 'God has given you a dream, you can live that dream, so don't start waiting for it to come'; and:

'So if God knows today you are going to be HIV positive and tomorrow you will be stigmatised, God has known that and $\mathrm{He}$ has made a plan. He will never give you more problems you can handle. So whatever challenge you are having now, God knows you are having it and has made a plan to overcome it. If you want to be a teacher, HIV will not prevent you from being a teacher. If you want to be a musician your status will not prevent you from being it.'

\section{Greater awareness of HIV stigma and the realities of stigma and disclosure}

Participants developed a greater awareness and understanding of what HIV stigma is and the realities of stigma and disclosure that PLWH experience when they disclose their status. Two categories developed from the data.

\section{Awareness of HIV stigma}

The participants realised for the first time during the intervention what HIV stigma is. They indicated that no one ever told them about the extent of stigma with which PLWH have to cope. One participant noted before the intervention: 'I knew nothing, I just knew if you have HIV you are going to die'. The intervention helped participants become aware of the consequence of stigma within the lives of PLWH and their community. The above-mentioned consequences included gossip, abuse, rejection by their families, job loss, illness, depression and suicide.

\section{Awareness of disclosure realities}

During the workshop, PLWH openly disclosed their HIVpositive status to the participants because they felt safe to do it and felt empowered to handle it through the initial workshop on 'responsible disclosure management', which was only presented to PLWH. The spiritual leaders saw how disclosing unburdens PLWH. People living with HIV expressed their happiness to let go of their secret and share their status with the participants. The participants appreciated how disclosing freed $P L W H$, '... free, like they didn't have HIV'. It made participants happy to hear PLWH disclose and be'... free to be with them'. However, participants realised that PLWH might have negative expectations of disclosure because of traumatic past disclosures. When their own families stigmatise them, they do not expect other people to accept their status:

'But now if your immediate family ... don't want you in her room, don't want to share a cup of tea, don't want to eat with you or drink with you. So if you have this problem of treatment in the house, how are people from outside going to treat you?'

Consequently, disclosure can change relationships sometimes for the worse. Participants described disclosure as an emotional experience filled with shock, hurt and a sadness that 'broke [their] heart[s]'. Yet, they realised that for PLWH not disclosing is painful to the point where '... if you keep it to yourself you die inside'. The example of PLWH self-confidently disclosing their status inspired some of the spiritual leaders to go for an HIV test to '... know [their own] status and live free'.

\section{Experiences of the HIV stigma reduction workshops and project outcomes}

Three categories emerged from the data in the last theme: The spiritual leaders had a positive experience of the outcomes of the HIV stigma reduction workshops and the community projects which they had to plan and execute; they were excited about the newly acquired knowledge, attitudes and skills they gained; and they could see the change as successful outcomes of the impact of the workshops and the projects.

\section{Positive outcomes of HIV stigma reduction workshop and project}

Spiritual leaders had a positive experience of the workshops and project, expressing their joy of having had the opportunity to be involved. In particular, they were happy that 'traditional healers as well as pastors [were] being group[ed] together'. They got a better understanding of one another. After the project, they could see more people becoming involved with HIV stigma reduction actions offered by traditional healers, religious leaders and people of the community: 'They can come and be taught more if they want and you can find that there's a traditional healer, a pastor and peers all working together'. As part of a dedicated group that had to implement their project, they experienced solidarity, support and teamwork. This was a new experience for specifically the religious leaders ('... working together especially people who are different in religions is totally something very difficult to other people because our faith is not the same'). Nonetheless, they were very motivated to do the project, to overcome obstacles and to succeed in their communities. Participants felt attendance was important and they encouraged others to get involved with the project. These projects touched the hearts of not only the participants but their communities as well: 'I think that it is good to touch people's hearts. So, people can take this thing very, very serious... It is good to touch people's lives'. The project taught the participants things that made them feel empowered, but it also posed challenges such as acting as leaders, and lacking finances to attend planning meetings (which resulted in poor attendance). In one of the projects, the participants were disappointed because the community attendance was poorer than they anticipated.

\section{Newly acquired knowledge, attitudes and behaviours}

The participants indicated that the intervention had been a life-changing experience for them. They felt that they had acquired new knowledge and experienced a change in attitudes and behaviours towards PLWH that developed throughout the workshops and the project. The intervention gave them new perspectives on the way they work with PLWH. They realised that a person's:

\footnotetext{
'spiritual affiliation is not important. What is important is your fight against stigmatising, how we have to fight it and how people have to cope with it. So that was an eye opener to me.'
} 
They felt strongly that they and others in the community should love, support and encourage PLWH. The families of PLWH should be the first line of support when they disclose. They should be the one's saying: '... don't worry, God is in control and they are there for you'. They should tell PLWH '... that you are my child and you will always be my child no matter what. I love you regardless of your illness'. They indicated that through building good relationships between family and friends of PLWH, they could lead the community to a more respectful manner of treating PLWH which advocates for their acceptance. The projects helped them gain new knowledge of HIV and stigma, which led to learning new ways in how to interact with PLWH: 'It gives me knowledge, because to be a different pastor and to change people, it means a lot to the people who have no power'. They felt that they no longer want to stigmatise PLWH, but that they should rather help PLWH. They should not change their behaviour towards PLWH after disclosure: 'Wouldn't treat them any different to how I used to treat them before'. They learnt new skills, such as how to deal with PLWH; how to relate, support and encourage them; how to cope with stress; how to do fundraising; how to write a play; how to plan a project; and how to overcome unforeseen challenges.

\section{Successful change outcomes}

The intervention (workshops and project) brought about definite change. Afterwards, they wanted to fight stigma and advocate against it. They had managed to put their differences aside and focused on reducing HIV stigma: 'There we had spiritual leaders, we have sangomas, we had Christians, even if you are Muslim, there was one. Your spiritual affiliation is not important'. They believed that change with regard to stigma is possible in their own communities, because some had seen circumstances in their communities changing:

'We can change people's minds. Then, if a community that have pastor or someone like me and others, so that they can do this thing, the community can become a better community.'

Participants were happy to have had a role in the observed change and planned to continue to teach other people. They have taken the lessons of the intervention into their daily lives: 'So far, I've been talking to people. Sometimes, in the church I take the pamphlet and I preach about the pamphlet. I see that many people start to understand and they start to become open' and 'I use religion by quoting that God doesn't want you to shun a person and in so I bring the shunning of people in stigma, I bring that together in that presentation and I tell people about'. Participants felt that it is knowledge that will bring change towards PLWH and how they are treated, because they will lead by example: 'It gave me knowledge to be a different pastor and to change people. It means a lot to the people who have got no powers'. The participants felt happy that PLWH stand up for themselves and take control of their lives and 'participated in that workshop ... working with us. Doing things the way they are supposed to do'. This resulted in the spiritual leaders' changed attitudes towards HIV that should be treated as any other disease:
'PLWH didn't do it on purpose and people who aren't ill like to make it seem as if this person brought in on to themselves. There is no one who wants to be sick.'

\section{Practical implications and lessons learnt}

The value of the study can be drawn from understanding the practical implications of the findings and drawing on lessons learnt for future guidance.

The study has reported that following participation in a community-based HIV stigma reduction intervention, spiritual leaders recognised their lack of appreciation and understanding of the plight of PLWH. Practically, it emerged that spiritual leaders need to understand the role of spirituality in the lives of PLWH. Stigmatising behaviour (sometimes unintentional) can create barriers between spiritual leaders, the community and PLWH. There seem to be a perceived unaccountability of spiritual leaders to unite regarding HIV stigma reduction. The following lessons learnt regarding the community-based HIV stigma interventions provide guidance in this regard:

- Spiritual leaders can become more aware of the painful realities and exclusion PLWH in their communities face.

- A change of attitude in the spiritual leaders was facilitated by including them in the intervention.

- Spiritual leaders can individually or as part a team play a significant and visible role in the fight against HIV stigma.

- Inclusion in a community-based HIV stigma reduction intervention can unite spiritual leaders and PLWH to bring about a positive shift in the attitudes of communities.

- Faith communities can make a meaningful contribution to facilitate such a shift in attitudes and they can advocate against HIV stigmatisation within their communities.

\section{Limitations of the study}

The small sample size may be a limitation to this study, but a large sample size could have compromised the therapeutic nature of the intervention. If more time could have been spent with participants, the impact could have been even more intense. A follow-up short intervention could also have strengthened the impact.

\section{Conclusion}

As described in literature (e.g. Miller 2009:277-278), few interventions directly involve spiritual leaders in attempts to reduce HIV stigma in communities. This article reports on the value of involving PLWH and spiritual leaders in the same community-based HIV stigma reduction intervention. Spiritual leaders saw themselves playing a much greater part in reducing stigma in their own congregations and their communities at large. Through increasing the community's knowledge about HIV stigma and exposure to PLWH, boundaries can be broken down and fear of HIV reduced. After the intervention, spiritual leaders accepted PLWH more, became more empathic towards them and also became aware of their own ignorance of the realities that PLWH have 
to face and how they have failed PLWH in their congregations. Spiritual leaders should encourage PLWH and support them so that they do not have to face such hardships alone. Spiritual leaders should take on a much stronger role in making PLWH's lives bearable, giving them hope and providing spiritual support, as also mentioned by De la Porte (2016:5). Spiritual leaders should help PLWH face disclosure challenges by providing a safe environment and offering unconditional support. If spiritual leaders are equipped with project skills, they will be afforded the opportunity to become leaders in the fight against HIV stigma and will start to initiate change in their own congregations and communities. Spiritual leaders should build relationships (regardless of spiritual affiliation) to fight against stigma and to change the lives of people in their communities. Phillips (2005:336) emphasise the need to practice 'compassion, love and understanding' in this regard.

Spiritual leaders are deeply involved in South African communities and have the respect of community members. They can thus play an important role in becoming agents of change that can influence what happens with regard to HIV stigma in their community. We recommend that participatory interventions for HIV stigma reduction specifically targeting spiritual leaders be developed and implemented.

\section{Recommendations}

It is recommended that the HIV stigma reduction intervention as developed here can in future be implemented to meaningfully target spiritual leaders (involving both traditional healers and religious leaders) in realising their responsibility and involvement with HIV stigma. We stress that PLWH should be included at the same time in the intervention to strengthen their relationships. We recommend that by building knowledge and understanding of HIV stigma, the expected effect should be retained. The practical application of the intervention should also in future activate the internal leadership of participants. We recommend that the intervention can be implemented without change in both urban and rural settings. We also recommend that after 3 months a small booster follow-up session should be conducted to strengthen the impact.

\section{Acknowledgements}

The authors would like to thank Mrs Poncho Mulaudzi, a research assistant, for her dedication. They also thank all fieldworkers for their hard work. A special word of appreciation goes to all the participants in this study. The authors received financial support from South AfricaNetherlands Research Programme on Alternatives in Development (SANPAD) for the research in the form of research funds.

\section{Competing interests}

The authors declare that they have no financial or personal relationships which may have inappropriately influenced them in writing this article.

\section{Authors' contributions}

G.K. preformed the data analysis and assisted in conceptualising, drafting and finalising the article. M.G. as the project leader conceptualised the study, conducted the intervention, supported the data analysis, drafted the article and finalised the article. R.L. was a facilitator during the intervention with spiritual leaders and peer-reviewed the article.

\section{References}

Ammon, N., Mason, S. \& Corkery, J.M., 2018, 'Factors impacting antiretroviral therapy adherence among human immunodeficiency virus-positive adolescents in subSaharan Africa: A systematic review', Public Health 157, 20-31. https://doi. org/10.1016/j.puhe.2017.12.010

Alonzo, A.A. \& Reynolds, N.R., 1995, 'Stigma, HIV and AIDS: An exploration and elaboration of a stigma trajectory', Social Science \& Medicine 41(3), 303-315. https://doi.org/10.1016/0277-9536(94)00384-6

Apinundecha, C., Laohasiriwong, W., Cameron, M.P. \& Lim, S., 2007, 'A community participation intervention to reduce HIV/AIDS stigma, Nakhon Ratchasima province, northeast Thailand', AIDS Care 19(9), 1157-1165. https://doi.org/ 10.1080/09540120701335204

Baumgardner, S.R. \& Crothers, M.K., 2010, Positive psychology, Pearson, Upper Saddle River, NJ.

Botma, Y., Greeff, M., Mulaudzi, F.M. \& Wright, S.C.D., 2010, Research in health sciences, Pearson, Johannesburg, South Africa.

Brown, L., Macintyre, K. \& Trujillo, L., 2003, 'Interventions to reduce HIV/AIDS stigma: What have we learned?', AIDS Education \& Prevention 15(1), 49-69. https://doi. org/10.1521/aeap.15.1.49.23844

Clarke, M., Charnley, S. \& Lumbers, J., 2011, 'Churches, mosques, and condoms: Understanding successful HIV and AIDS interventions by faith-based organisations', Development in Practice 21(1), 3-17. https://doi.org/10.1080/09614524.2011. 530227

Creswell, J.W., 2014, Research design: Qualitative, quantitative, and mixed methods approaches, 4th edn., Sage, London.

De la Porte, A., 2016, 'Spirituality and healthcare: Towards holistic peoplecentred healthcare in South Africa', HTS Teologiese Studies/Theological Studies 72(4), 1-9. https://doi.org/10.4102/hts.v72i4.3127

French, H., Greeff, M. \& Watson, M.J., 2014, 'Experiences of people living with HIV and people living close to them of a comprehensive HIV stigma reduction community intervention in an urban and a rural setting: Original article', Journal of Social Aspects of HIV/AIDS 11(1), 105-115. https://doi.org/10.1080/17290376. of Social Aspects

French, H., Greeff, M., Watson, M.J. \& Doak, C.M., 2015, 'A comprehensive HIV stigmareduction and wellness-enhancement community intervention: A case study', Journal of the Association of Nurses in AIDS Care 26(1), 81-96.

Gausset, Q., Mogensen, H.O., Yameogo, W.M.E., Berthé, A. \& Konaté, B., 2012, 'The ambivalence of stigma and the double-edged sword of HIV/AIDS intervention in Burkina Faso', Social Science \& Medicine 74(7), 1037-1044. https://doi.org/ 10.1016/j.socscimed.2011.11.044

Gilbert, L., 2016, “"The mercurial piece of the puzzle”: Understanding stigma and HIV/ AIDS in South Africa', Sahara Journal of the Social Aspects of HIV/AIDS 13(1), 8-16. https://doi.org/10.1080/17290376.2015.1130644

Hanmer, S., Greenberg, A. \& Keshavarzian, G., 2009, 'Religious communities take the lead', Family and Community Ministries 23(2-3), 52-58.

Hodes, R., 2014, Broadcasting the pandemic: A history of HIV on South African television, Human Sciences Research Council, Cape Town.

Holzemer, W.L., Uys, L., Makoae, L., Stewart, A., Phetlhu, R., Dlamini, P.S. et al., 2007, 'A conceptual model of HIV/AIDS stigma from five African countries', Journal of Advanced Nursing 58(6), 541-551. https://doi.org/10.1111/j.1365-2648.2007. 04244.x

Human Sciences Research Council (HSRC), 2015, The people living with HIV Stigma Index: South Africa 2014. Summary report, viewed 24 October 2017, from http:// www.stigmaindex.org/sites/default/files/reports/Summary-Booklet-on-StigmaIndex-Survey\%20South\%20Africa.pdf

Joint United Nations Programme on HIV/AIDS, 2014, 90-90-90 - An ambitious treatment target to help end the AIDS epidemic, viewed 15 June 2015, from http://www.unaids.org/en/resources/documents/2014/90-90-90

Joint United Nations Programme on HIV/AIDS, 2015, Community-based antiretroviral therapy delivery: Experiences from MSF, viewed 12 June 2015, from http://www. unaids.org/en/resources/documents/2015/20150420_MSF_UNAIDS_JC2707

Joint United Nations Programme on HIV/AIDS, 2018, HIV, the Law and Human Rights in the African Human Rights System: Key challenges and opportunities for rightsbased responses - Report on the study of the African Commission on Human and Peoples' Rights, viewed 12 April 2018, from http://www.unaids.org/sites/default/ files/media_asset/HIV_Law_AfricanHumanRightsSystem_en.pdf

Keikelame, M.J., Murphy, C.K., Ringheim, K.E. \& Woldehanna, S., 2010, 'Perceptions of HIV/AIDS leaders about faith-based organisations' influence on HIV/AIDS stigma in South Africa', African Journal of AIDS Research in Nursing \& Health 9(1), 63-70. https://doi.org/10.2989/16085906.2010.484571 
Krauss, B.J., Godfrey, C.C., O’Day, J. \& Freidin, E., 2006, 'Hugging my uncle: The impact of a parent training on children's comfort interacting with persons living with HIV',
Journal of Pediatric Psychology 31(9), 891-904. https://doi.org/10.1093/jpepsy/ jsj099

Kremer, H. \& Ironson, G., 2014, 'Longitudinal spiritual coping with trauma in people with HIV: Implications for health care', AIDS Patient Care \& STDs 28(3), 144-154. https://doi.org/10.1089/apc.2013.0280

Kwansa, B.K., 2010, 'Complex negotiations: "Spiritual" therapy and living with HIV in Ghana', African Journal of AIDS Research 9(4), 449-458. https://doi.org/10.2989/ 16085906.2010.545662

Landman, C., 2014, 'The church as a HIV-competent faith community: An assessment of Christian AIDS Bureau for Southern Africa's churches, channels of hope training: Original research', Verbum et Ecclesia 35(2), 1-6. https://doi.org/10.4102/ve. v35i2.1348

Leclerc-Madlala, S., Green, E. \& Hallin, M., 2016, 'Traditional healers and the "FastTrack" HIV response: Is success possible without them?', African Journal of AIDS Research 15(2), 185-193. https://doi.org/10.2989/16085906.2016.1204329

Louwrens, M.H., Greeff, M. \& Manyedi, M.E., 2016, 'A community-based HIV stigma reduction intervention for people living with HIV and their partners', Africa Journal of Nursing \& Midwifery 18(2), 6-26. https://doi.org/10.25159/2520-5293/935

Masquillier, C., Wouters, E., Mortelmans, D. \& le Roux Booysen, F., 2015, 'The impact of community support initiatives on the stigma experienced by people living with HIV/AIDS in South Africa', AIDS And Behavior 19(2), 214-226. https://doi.org/ 10.1007/s10461-014-0865-1

Mayers, C. \& Johnston, D., 2008, 'Spirituality: The emergence of a working definition for use within healthcare practice', Implicit Religion 11(3), 265-275.

Miller, A.N., 2009, 'Religion in the African public [health] square: The case of HIVrelated stigma', Journal of Communication \& Religion 32(2), 268-288.

Nemutandani, S.M., Hendricks, S.J.H. \& Mulaudzi, F.M., 2015, 'HIV/AIDS and TB knowledge and beliefs among rural traditional health practitioners in Limpopo Province, South Africa', African Journal for Physical, Health Education, Recreation and Dance 1(1), 119-134.

Norder, W.A.J., Peters, R.P.H., Kok, M.O., van Elsland, S.L., Struthers, H.E., Tutu, M.A. et al., 2015, 'The church and paediatric HIV care in rural South Africa: A qualitative study', AIDS Care 27(11), 1404-1409. https://doi.org/10.1080/09540121.2015.1114987

Okun, B.F., 1992, Effective helping: Interviewing and counseling techniques, Brooks/ Cole, Pacific Grove, CA.

Olaore, I.B. \& Olaore, A.Y., 2014, 'Is HIV/AIDS a consequence or divine judgment? Implications for faith-based social services. A Nigerian faith-based university's study', Journal of Social Aspects of HIV/AIDS 11(1), 20-25. https://doi.org/10.108 study', Journal of Social Aspec
$0 / 17290376.2014 .910134$

Park, A., 2016, 'HIV used to be a death sentence. Here's what's changed in 35 years', TIME Health, 01 December, viewed 08 June 2017, from http://time.com/4585537/ world-aids-day-hiv/

Parker, R. \& Aggleton, P., 2003, 'HIV and AIDS-related stigma and discrimination: A conceptual framework and implications for action', Social Science \& Medicine 57(1), 13-24. https://doi.org/10.1016/S0277-9536(02)00304-0

Phillips, E., 2005, 'Stigmatization and the silence of the church', African Ecclesiastical Review 47-48(4-1), 328-340.

Pretorius, J.B., Greeff, M., Freeks, F.E. \& Kruger, A., 2016, 'A HIV stigma reduction intervention for people living with HIV and their families', Health SA Gesondheid 21(1), 187-195. https://doi.org/10.4102/hsag.v21i0.952
Sandelowski, M., 2000, 'Focus on research methods. Whatever happened to qualitative description?', Research in Nursing \& Health 23(4), 334-340. https:// doi.org/10.1002/1098-240X(200008)23:4\%3C334::AID-NUR9\%3E3.0.CO;2-G

Sengupta, S., Banks, B., Jonas, D., Miles, M.S. \& Smith, G.C., 2011, 'HIV interventions to reduce HIV/AIDS stigma: A systematic review', AIDS And Behavior 15(6), 1075-1087. https://doi.org/10.1007/s10461-010-9847-0

Slomka, J., Lim, J., Gripshover, B. \& Daly, B., 2013, 'How have long-term survivors coped with living with HIV?', Journal of the Association of Nurses in AIDS Care 24(5), 449-459. https://doi.org/10.1016/j.jana.2012.09.004

Stangl, A.L., Lloyd, J.K., Brady, L.M., Holland, C.E. \& Baral, S., 2013, 'A systematic review of interventions to reduce HIV-related stigma and discrimination from 2002 to 2013: How far have we come?', Journal of the International AIDS Society 16(3), 1-14. https://doi.org/10.7448/IAS.16.3.18734

Statistics South Africa, 2004, Census 2001: Primary tables South Africa. Census '96 and 2001 compared, Statistics South Africa, Pretoria, South Africa.

Statistics South Africa, 2016, Community survey 2016 provinces at a glance, viewed 24 October 2017, from http://cs2016.statssa.gov.za/wp-content/uploads/2016/06/ CS-2016-Provinces-at-a-glance.pdf

Statistics South Africa, 2017, Mid-year population estimates, 2017, viewed 12 April 2018, from http://www.statssa.gov.za/publications/P0302/P03022017.pdf

Thomas, L., Schmid, B., Gwele, M., Ngubo, R. \& Cochrane, J.R., 2006, 'Let us embrace' The role \& significance of a faith-based initiative in HIV and AIDS work, African Religious Health Assets Programme, Cape Town, South Africa.

Treves-Kagan, S., Steward, W.T., Ntswane, L., Haller, R., Gilvydis, J.M., Gulati, H. et al., 2016, 'Why increasing availability of ART is not enough: A rapid, community-based study on how HIV-related stigma impacts engagement to care in rural South Africa', BMC Public Health 16, 1-13.

Uys, L., Chirwa, M., Kohi, T., Greeff, M., Naidoo, J, Makoae, L. et al., 2009, 'Evaluation of a health setting-based stigma intervention in five African countries', AIDS Patient Care and STDs 23(12), 1059-1066. https://doi.org/10.1089/apc.2009.0085

van der Walt, I.J. \& Vorster, J.M., 2016, 'The relationship between moral intervention strategies and the stigmatisation of people living with HIV - A Christian perspective', HTS Teologiese Studies/Theological Studies 72(3), a3384. https://doi. perspective', HTS Teologiese
org/10.4102/hts.v72i3.3384

van Wyngaard, A., 2013, 'Addressing the spiritual needs of people infected with and affected by HIV and AIDS in Swaziland', Journal of Social Work in End-of-Life \& Palliative Care 9(2-3), 226-240. https://doi.org/10.1080/15524256.2013.794064

White, P., 2015, 'The concept of diseases and health care in African traditional religion in Ghana: Original research', HTS Teologiese Studies/Theological Studies 71(3), 1-7. https://doi.org/10.4102/hts.v71i3.2762

WHO, 2016, HIV/AIDS online Q\&A, viewed 12 June 2017, from http://www.who.int/ features/qa/71/en/

World Council of Churches, 2016, AIDS2016 pushes faith communities to respond to epidemic's new challanges, viewed 24 October 2017, from https://www. oikoumene.org/en/press-centre/news/aids2016-pushes-faith-communities-torespond-to-epidemic2019s-new-challenges-1

Wu, S., Li, L., Wu, Z., Liang, L.-J., Cao, H., Yan, Z. et al., 2008, 'A brief HIV stigma reduction intervention for service providers in China', AIDS Patient Care and STDs 22(6), 513-520. https://doi.org/10.1089/apc.2007.0198

Yin, R.K., 2009, Case study research: Design and methods, 4th edn., Sage, Los Angeles, CA. 